\title{
Tolerability, course and follow-up of specific immunotherapy using a modified ultra-rush procedure in children and adolescents with insect venom allergy
}

\author{
Jens-Oliver Steiß · Conrad Weber · Max Becker
}

Received: 21 February 2021 / Accepted: 28 June 2021 / Published online: 3 November 2021

(c) The Author(s) 2021

\begin{abstract}
Summary
Background Specific immunotherapy with insect venom (hymenoptera venom (HG)-AIT) is an effective and the only causal treatment for patients with systemic reactions due to IgE-mediated insect venom allergy. The present study investigated the quality of care after bee and wasp venom allergy, the tolerability of modified ultra-rush immunotherapy and the course after the conclusion of maintenance therapy in children and adolescents. Studies on the quality of life of children with insect venom allergy are scarce. Methods The efficacy, safety and tolerability of an ultra-rush protocol was analysed in 114 patients aged 4-17 years with insect venom allergy. After the end of HG-AIT, patients were contacted by questionnaire and asked to report on the quality of care as well as the course of insect venom allergy, including accidental stinging events. Quality of life was validated using the established questionnaire VQLQ-d (Vespid Quality of Life Questionnaire), which is also used for bee venom allergy patients.

Results Discontinuation of the initial therapy was not necessary in any patient. Side effects were mostly mild and did not require treatment. In 16 patients, a new sting reaction occurred during maintenance therapy, in another 15 patients a sting event was documented after cessation of HG-AIT. The intensity of the reaction to the accidental insect bite according
\end{abstract}

Prof. Dr. J.-O. Steiß $(\bowtie) \cdot$ M. Becker

Paediatric Pneumology and Allergology, Centre for

Paediatric and Adolescent Medicine, University Hospital

Giessen and Marburg GmbH, Justus Liebig University

Giessen, Feulgenstraße 12, 35385 Giessen, Germany

Jens-Oliver.Steiss@paediat.med.uni-giessen.de

Dr. C. Weber

Institute of Virology and Immunobiology, Julius Maximilians

University Würzburg, Würzburg, Germany to the severity classification after Ring and Messmer decreased from an average of 2.3 to 0.9 in these patients. This corresponds to a decrease of $61 \%$. An emergency kit was carried by $70 \%$ of the patients, the expiry date of which, however, had already passed in almost $40 \%$ of the respondents. After the end of the therapy, most patients were not under any medical care or had never been to a check-up (92\%). The evaluation of the VQLQ-d showed a medium to low level of stress during or after therapy.

Discussion Ultra-rush AIT in childhood and adolescence is safe, tolerable and effective. HG-AIT has a lasting positive effect on the health-related quality of life of patients. However, after the end of HG-AIT, there are deficits in the follow-up and care of the patients.

Keywords Allergen immunotherapy · Insect venom allergy · Children · Quality of life · Systemic adverse reaction

\section{Abbreviations}

AIT Allergen immunotherapy

EAACI European Academy of Allergology and Clinical Immunology

FceRI Fc epsilon receptor 1

HG Hymenoptera venom

HG-AIT Hymenoptera venom-allergen immunoIgE Immunoglobulin E

SIT Specific immunotherapy

Th-Zellen T helper cells

Th1 Type 1 helper cell

Th2 Type 2 helper cell

VQLQ-d Vespid Allergy Quality of Life Questionnaire (Fragebogen Lebensqualität bei Wespengiftallergie) 


\section{Introduction}

Sensitization to hymenopteran venoms can be detected in up to $25 \%$ of adults and $50 \%$ of children [1]. Most of these are clinically irrelevant sensitizations. According to European studies, the frequency of a systemic reaction is 0.3 to $7.5 \%$ in adults and up to $3.4 \%$ in children [2]. Specific immunotherapy with bee and/or wasp venom (hymenopteran venom/HGAIT) is the only causal treatment option for insect venom allergy and is associated with a high success rate. HG-AIT is indicated in patients with a systemic anaphylactic sting reaction and evidence of IgE-mediated sensitization. These patients should be prescribed an emergency kit consisting of an epinephrine auto-injector, an oral corticosteroid and an antihistamine [1-3]. Regular education of patients and/or parents is necessary. In children with only cutaneous anaphylactic sting reactions, the indication for HGAIT may be cautious, as the severity of further stings does not seem to increase without HG-AIT [4]. In addition, Lange et al. demonstrated that children with insect venom allergy who have not received HG-AIT usually have milder reactions when stung again. Severe systemic reactions are observed in $18 \%$ of untreated children [5].

Different regimens exist to achieve a maintenance dose of $100 \mu \mathrm{g}$ (micrograms) of the corresponding toxin for both children and adults [6]. For some years now, the initial therapy of HG-AIT in children has mostly been carried out according to an ultra-rush procedure within 2-3 days. Once the maintenance dose has been reached, this is initially continued weekly, then at 2-week intervals and finally every 4 weeks on an outpatient basis for 3-5 years [7-9].

Particularly in childhood, sting anaphylaxis is often associated with stressful thoughts and fears, parents' concerns about their children's outdoor activities or other later restrictions. Studies in adults show that the experience of a systemic sting reaction leads to a decrease in quality of life [10] and is not infrequently associated with more severe anxiety symptoms [11]. After all, about $43 \%$ of children are stung again in the next 10 years after HG-AIT [12]. Studies on the quality of life of children with insect venom allergy are scarce.

In our study, we analysed the success, feasibility, follow-up and quality of life in children and adolescents of HG-AIT for insect venom allergy. We examined in detail the reality of care after bee and wasp venom anaphylaxis, the tolerability of ultra-rush AIT and the subsequent course after the end of maintenance therapy in young adulthood.

\section{Patients and methodology}

In all, 114 patients (71 boys, 43 girls) aged $4-17$ years with insect venom allergy who underwent ultra-rush AIT between 2002 and 2017 were included in the study. Following a modified ultra-rush protocol, insect venom was applied subcutaneously in seven dose increments $(0.01 \mu \mathrm{g}, 0.1 \mu \mathrm{g}, 1 \mu \mathrm{g}, 10 \mu \mathrm{g}, 20 \mu \mathrm{g}$, $40 \mu \mathrm{g}$ and $80 \mu \mathrm{g}$ ) over a $6-7 \mathrm{~h}$ period on the first day of hospital admission. The final dose of $100 \mu \mathrm{g}$ was administered to the patients on the morning of the second inpatient day (Fig. 1).

Inclusion criteria were a grade II-IV allergic reaction according to Ring and Messmer (RM) [13] or grade I and a high risk of exposure (e.g. beekeeping in the family or neighbourhood) or impairment of quality of life, as well as the detection of specific IgE antibodies and/or a positive skin prick test. All induction treatments were carried out as inpatients, and local and systemic reactions were documented. AIT was performed with a lyophilised, standardised bee venom of Apis mellifera or wasp venom of Vespula spp. (Venomil ${ }^{\circledR}$ Bee, Venomil ${ }^{\circledR}$ Wasp, Bencard Allergie, Munich, Germany). The study was approved by the responsible ethics committee.

After the end of the HG-AIT, the patients, some of whom were now adults, were contacted by mail with a stamped envelope and asked to report on the course of the insect venom allergy. In addition to general demographic information, the questionnaire evaluated the main areas of type and severity of the anaphylactic reaction, disease management (initial treatment and follow-up therapy), use of emer-
Fig. 1 Protocol ultra-rush AIT with gradual extension of the maintenance dose to an interval of four weeks in 114 patients with insect venom allergy (age 4-17 years). $\mathrm{ml}$ millilitres, $\mu g$ micrograms

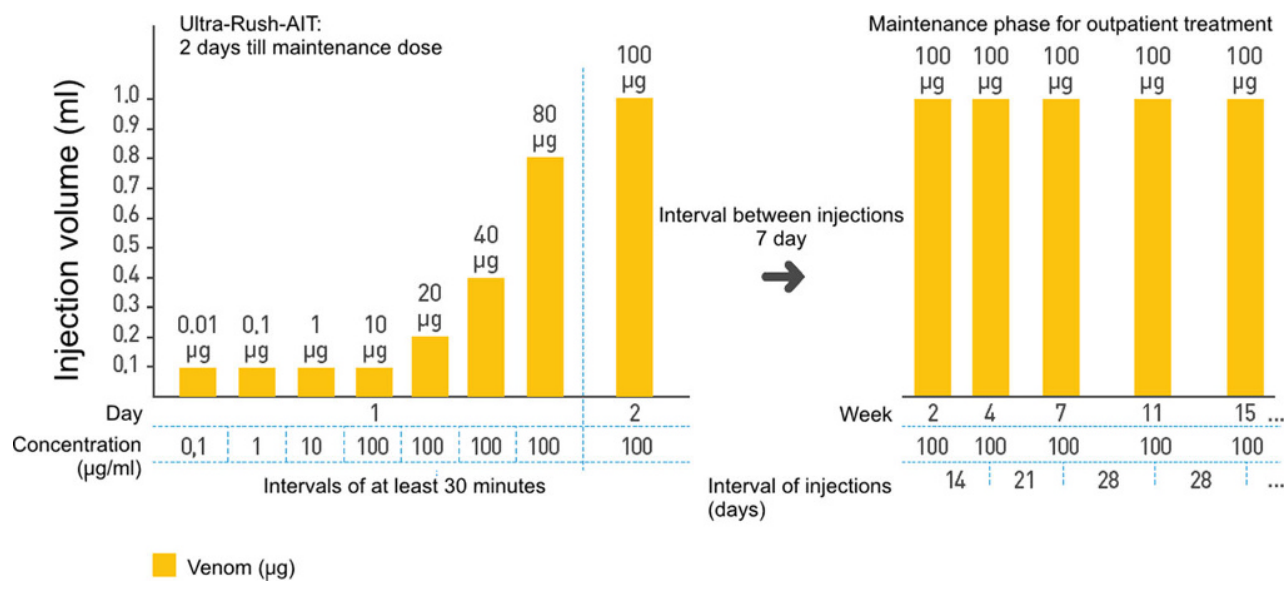


Table 1 Demographic and clinical patient data before starting HG-AIT

\begin{tabular}{llll} 
& $\begin{array}{l}\text { Patients } \\
\text { (total) }\end{array}$ & $\begin{array}{l}\text { Patients with bee } \\
\text { venom allergy }\end{array}$ & $\begin{array}{l}\text { Patients with wasp } \\
\text { venom allergy }\end{array}$ \\
\hline Patients, $n(\%)$ & $114(100)$ & $55(48.2)$ & $59(51.8)$ \\
\hline Age, years & $9.71 \pm 3.1$ & $9.54 \pm 3.34$ & $9.74 \pm 3.15$ \\
\hline Minimum, years & 4 & - & - \\
\hline $\begin{array}{l}\text { Maximum, years } \\
\text { Gender, } n \text { (\%) }\end{array}$ & 17 & - & - \\
\hline Male & $71(62.2)$ & $27(23.7)$ & $44(38.6)$ \\
\hline Female & $43(37.7)$ & $28(24.6)$ & $15(13.2)$ \\
\hline Severity of sting reaction according to Ring and Messmer [13], $n(\%)$ \\
Grade I & $25(21.9)$ & $13(11.4)$ & $12(10.5)$ \\
Grade II & $59(51.8)$ & $26(22.8)$ & $33(29)$ \\
Grade III & $29(25.4)$ & $15(13.1)$ & $14(12.3)$ \\
Grade IV & $1(0.9)$ & $1(0.9)$ & $0(0)$
\end{tabular}

gency medication (emergency kit), course of HG-AIT and follow-up (check-ups with general practitioner/ specialist). In addition, the German version of the standardised questionnaire for wasp venom allergy (VQLQ-d, Vespid Quality of Life Questionnaire) was included to assess the quality of life; this questionnaire is also used for bee venom allergy patients. The questionnaire consists of a total of 14 questions concerning anxiety symptoms with their manifestations, psychological stress and stressful situations as well as avoidance and escape behaviour in insect venom allergic patients. Moreover, the patients were asked about the influence of the therapy on their quality of life by means of a visual analogue scale. They had the option to choose between a small (1) and large (10) improvement in quality of life. The data were analysed with the statistical software SPSS (IBM, Armonk, NY, USA). Descriptive statistics were preferred. Where appropriate, the Mann-Whitney U test was used for independent samples.

\section{Results}

In all, 55 of the 114 patients had bee venom allergy and 59 had wasp venom allergy. The age at initiation was comparable in both groups. In terms of gender distribution, the male gender was overrepresented in the group with wasp venom allergy, whereas the group with bee venom allergy was equally genderdistributed (Table 1).

\section{Index sting and primary medical care}

The retrospective analysis of the type of care after the initial sting event showed that 53 patients (46.5\%) were initially treated privately and then taken to hospital; 37 patients $(32.5 \%)$ were admitted to hospital by the ambulance service, including 7 patients (6.1\%) without medical escort and 30 patients $(26.3 \%)$ by an emergency ambulance (EMS). A total of 24 (21.1\%) patients were treated preclinically by a paediatrician in private practice, a general practitioner or the medical on-call service (Fig. 2). With $43.5 \%$ most of the sting events occurred in the home environment (house/ garden) with $43.5 \%$. All patients were treated with an emergency kit. The initial severity of the sting event according to Ring and Messmer (RM) is given in Table 1 .

\section{Introduction HG-AIT using modified ultra-rush protocol and tolerability}

The total cumulative dose according to the ultra-rush protocol was $251.11 \mu \mathrm{g}$ insect venom. Discontinuation of the initiation therapy was not necessary in any patient. No serious systemic reactions occurred in a total of 912 documented injections. The adverse reactions were mostly mild and did not require treatment. Erythema with a diameter of $<5 \mathrm{~cm}$ (centimetres) at the injection site was detectable in almost all

Fig. 2 Type of primary health care after the index bite

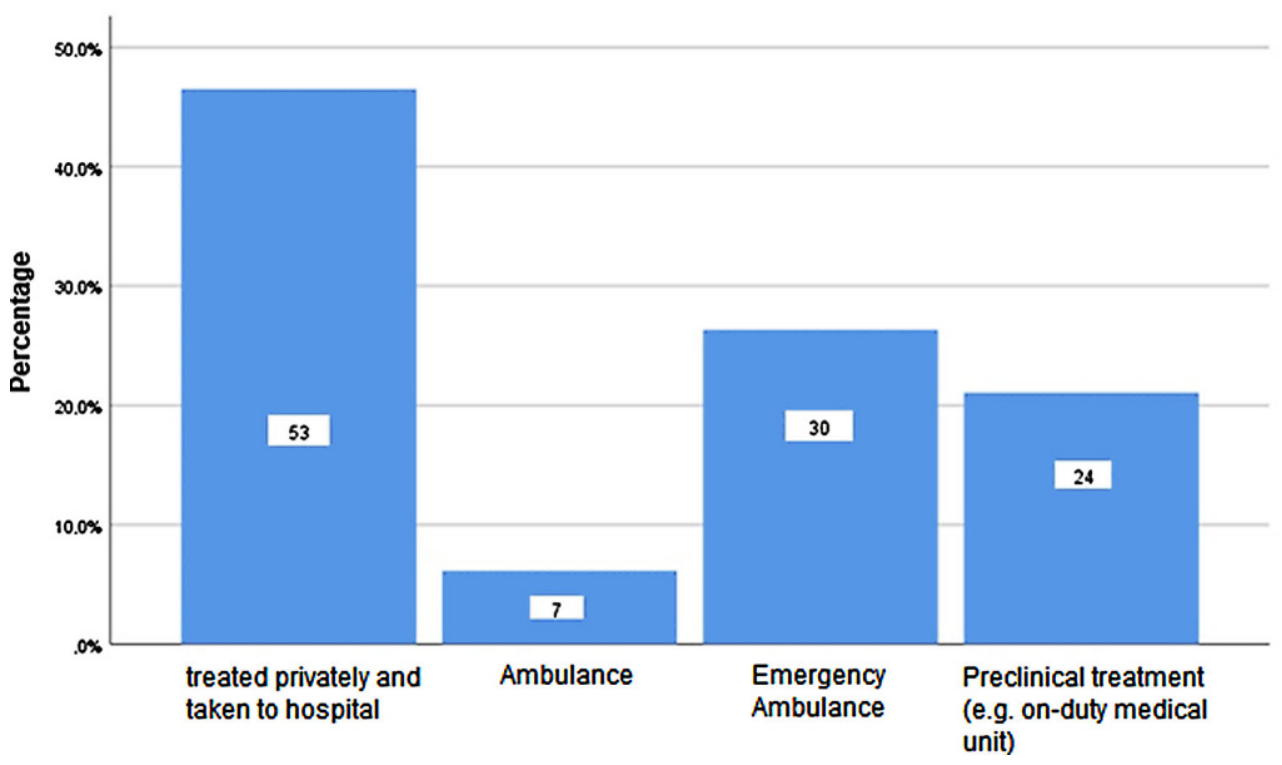


Table 2 Average severity of sting reactions according to Ring and Meßmer [13] ${ }^{\mathrm{a}}$

\begin{tabular}{|c|c|c|c|c|c|c|}
\hline \multirow[b]{2}{*}{ Inducing insect } & \multicolumn{3}{|c|}{ Sting event during AIT } & \multicolumn{3}{|c|}{ Sting event after completion of AIT } \\
\hline & $\begin{array}{l}\text { Patients, } \\
n(\%)\end{array}$ & $\begin{array}{l}\text { RM response initial } \\
\text { sting event (mean) }\end{array}$ & $\begin{array}{l}\text { RM response re-sting } \\
\text { event (mean) }\end{array}$ & $\begin{array}{l}\text { Patients, } \\
n(\%)\end{array}$ & $\begin{array}{l}\text { RM response initial } \\
\text { sting event (mean) }\end{array}$ & $\begin{array}{l}\text { RM response re-sting } \\
\text { event (mean) }\end{array}$ \\
\hline Bee & $5(31.25)$ & 2.2 & 1.4 & $9(60)$ & 2.1 & 1 \\
\hline Wasp & $11(68.75)$ & 2.2 & 0.9 & $6(40)$ & 2.7 & 0.8 \\
\hline Aggregate values & $16(100)$ & 2.2 & 1.1 & $15(100)$ & 2.3 & 0.9 \\
\hline
\end{tabular}

Table 3 Supply situation of patients with adrenaline auto-injectors

\begin{tabular}{|c|c|c|c|c|}
\hline Question & Patients (total), $n(\%)$ & Yes, $n(\%)$ & No, $n(\%)$ & No information, $n(\%)$ \\
\hline Have you been prescribed an adrenaline auto-injector? & $64(100)$ & $55(85.9)$ & $9(14.1)$ & $0(0)$ \\
\hline Do you still have it? & $55(100)$ & $39(70.9)$ & $16(29.1)$ & $0(0)$ \\
\hline Has the expiry date passed? & $39(100)$ & $15(38.4)$ & $23(59)$ & $1(2.6)$ \\
\hline Do you still carry it with you? & $39(100)$ & $31(79.5)$ & $7(17.9)$ & $1(2.6)$ \\
\hline Have you ever had to use it? & $55(100)$ & $3(5.5)$ & $50(90.9)$ & $2(3.6)$ \\
\hline In your opinion, were you sufficiently instructed in its use? & $55(100)$ & $49(89.1)$ & $5(9.1)$ & $1(1.8)$ \\
\hline Do you still feel able to use it successfully today? & $55(100)$ & $42(76.4)$ & $12(21.8)$ & $1(1.8)$ \\
\hline
\end{tabular}

patients, extensive redness ( $>5$ to maximum $20 \mathrm{~cm}$ ) in 18 patients $(16.1 \%)$ and wheals ( $>5$ to maximum $15 \mathrm{~cm})$ in 4 patients (3.6\%). Objectifiable systemic reactions were observed in 2 patients in the course of the initial therapy. One patient developed mild dyspnoea after the last administration of $100 \mu \mathrm{g}$ bee venom, but this improved immediately. Another patient developed urticaria on the trunk after administration of $80 \mu \mathrm{g}$ of bee venom, which resolved after application of dimetinden maleate and prednisolone.

\section{Maintenance therapy HG-AIT and sting reactions}

Maintenance therapy with $100 \mu \mathrm{g}$ of bee venom and wasp venom did not cause any problems in any of the patients. Apart from local reactions at the injection site, no side effects were described. The average duration of therapy was 4.1 years (median: 3.9 years; minimum: 1.8 years; maximum: 6.8 years). We achieved a response rate of $56.1 \%$ (64 out of 114). At the time of the survey, 10 patients $(15.6 \%)$ were still in maintenance therapy; on average, HG-AIT had already been completed for 5.7 years (median: 4.5 years; minimum: 0.2 years; maximum: 13.2 years). Among the patients who responded to the questionnaire, 16 patients $(25.0 \%)$ had another sting event during maintenance therapy. Of these, $81.2 \% \quad(n=13)$ tolerated the field sting without therapeutic intervention, 2 patients had a mild systemic reaction (grade II after $\mathrm{RM}$ ) and 1 patient additionally reacted with dyspnoea (grade III after RM). In a further 15 patients (23.4\%), a sting event was documented after completion of HG-AIT. Of these, $80 \%(n=12)$ showed tolerance and $20 \%(n=3)$ reacted with a mild systemic reaction (grade II according to $\mathrm{RM}$ ). These patients took one of the medications (corticosteroid or antihistamine) from their emergency kit as a precaution.
No medical consultation was required. The severity of reaction to an accidental sting decreased significantly in patients stung during maintenance therapy, on average from grade 2.2 (RM) before the start of SIT to grade $1.1(\mathrm{RM})$ during maintenance therapy $(p<0.001)$, equivalent to a $50 \%$ decrease (Table 2 and Fig. 3). In patients who were stung after the end of therapy, the mean value even decreased from grade $2.3(\mathrm{RM})$ to grade $0.9(\mathrm{RM})(p<0.001)$, equivalent to a decrease of $61 \%$ (Table 2 and Fig. 4). A total of 4 patients were stung once each during and after the end of therapy.

\section{Emergency kit provision}

According to patient information, $86 \%$ had received an emergency kit after the index event. Almost $71 \%$ still had an auto-injector during the entire follow-up of the HG-AIT and also afterwards; however the expiry date of which had already passed for almost $40 \%$ of the respondents. Nevertheless, $89 \%$ of the patients stated that they had been instructed in the proper use of the injector. Almost $80 \%$ of the patients carry the emergency kit with them, and $76 \%$ also feel able to use the auto-injector successfully. After the end of the therapy, most patients (92\%) were no longer under medical care or stated that they had never been seen for a check-up (Table 3).

\section{Quality of life}

The evaluation of the VQLQ-d showed a mean value of 5.7 (median: 5.8; $\mathrm{SD}=1.35$ ), which indicates a medium to low level of stress during or after HG-AIT. A high allergy-specific quality of life was detectable. A difference between men and women could not be shown $(p=0.95)$. Patients with bee venom AIT 


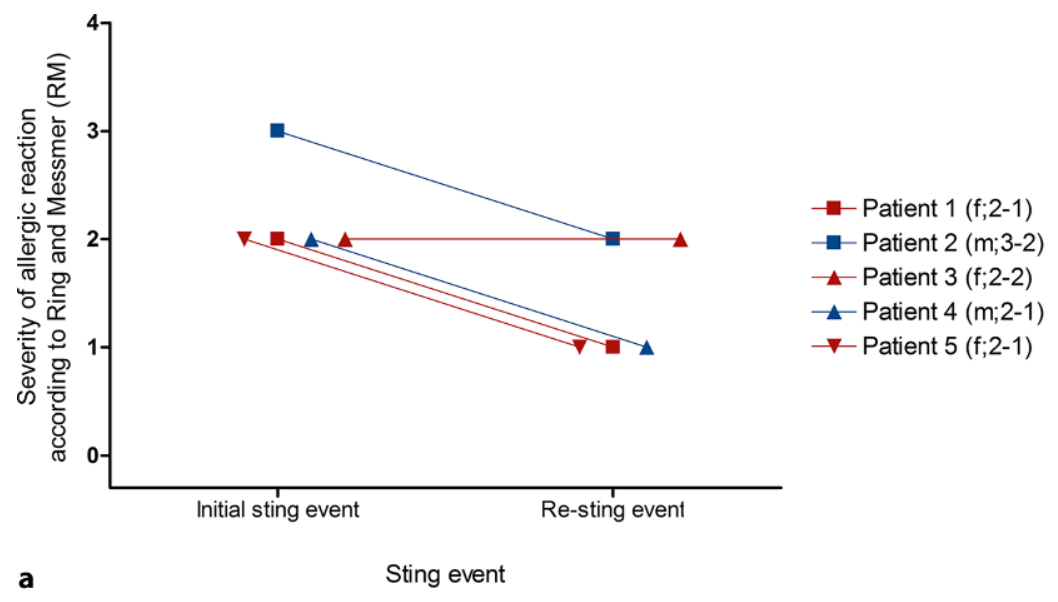

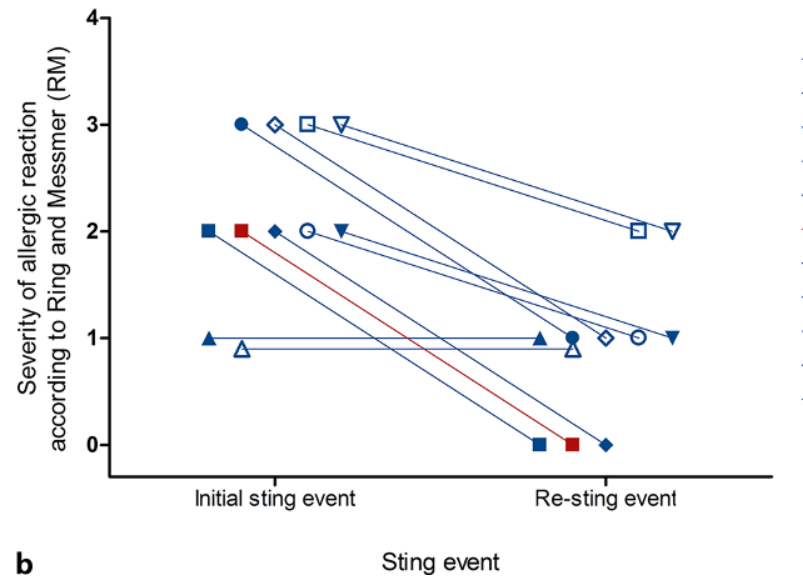

Fig. 3 Severity of allergic reaction according to Ring and Messmer [13] to accidental sting events during HG-AIT. a Data of the patient group with bee venom allergy. b Data of the

achieved a score of $5.9 \pm 1.03$, patients with wasp venom AIT 5.2 \pm 1.6 ; however, this difference was not significant ( $p=0.98$ ) (Fig. 5). A differentiation between the patients with "no reaction", "local reaction", "mild systemic reaction" (grade II according to RM) and "severe systemic reaction" (grade III according to RM) also revealed no differences with regard to quality of life. There is no evidence of a significant difference in quality of life between patients who had a field prick experience during $(p=0.23)$ or after completion $(p=0.10)$ of maintenance therapy depending on the severity of the reaction to the prick (Fig. 6 and 7). Similarly, there was no evidence of a significant difference in the quality of life of patients with expired or durable emergency kits or those who no longer carried them ( $p=0.13)$ (Fig. 8). The patient assessment of the subjective improvement in quality of life due to the therapy showed a mean value of 6.2 (median: $6.0 ; p=2.5$ ) (Fig. 9).

\section{Discussion}

The ultra-rush procedure is the shortest procedure for initiating HG-AIT and was first described by van der
- Patient $6(\mathrm{~m} ; 2-0)$

- Patient $7(\mathrm{~m} ; 1-1)$

$\rightarrow$ - Patient $8(\mathrm{~m} ; 2-1)$

- Patient $9(\mathrm{~m} ; 2-0)$

- Patient $10(\mathrm{~m} ; 3-1)$

- Patient $11(\mathrm{f} ; 2-0)$

口-Patient $12(\mathrm{~m} ; 3-2)$

$\triangle$ Patient $13(\mathrm{~m} ; 1-1)$

$\nabla$-Patient $14(\mathrm{~m} ; 3-2)$

$\checkmark$ Patient $15(\mathrm{~m} ; 3-1)$

- Patient $16(\mathrm{~m} ; 2-1)$

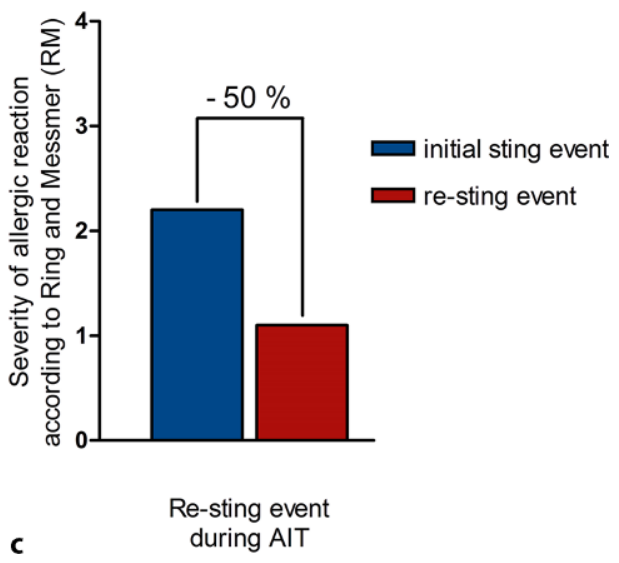

patient group with wasp venom allergy; c Aggregated values (mean). HG-AIT hymenoptera venom allergen immunotherapy, mean arithmetic mean, $m$ male, $w$ female

Zwan et al. [14]. In recent years, this scheme has increasingly found its way into the paediatric setting. Various studies confirm the safety of an ultra-rush protocol in children [6, 7]. The most common adverse reaction described is mostly local reactions at the injection site with redness and/or minor swelling [8, 9, 15-17]. Objective systemic reactions are hardly detectable or are usually of lesser clinical severity and can be managed well under inpatient conditions [15].

Children can be adjusted to the maintenance dose of $100 \mu \mathrm{g}$ within $24-36 \mathrm{~h}$ with a modified ultra-rush titration. In ultra-rush AIT with an increase within hours, the immunological effect is unclear. A shift from Th2 to Th1 lymphocytes or rather the activation of sufficient regulatory $\mathrm{T}$ cells is unlikely. It is conceivable that a refractory phase or anergy could develop through the consumption of mediators or an inhibition of IgE binding to mast cells, among other things, through down-regulation of the FceRI receptors on CD63 basophil granulocytes [18, 19].

The AIT effect could also depend on the total dose or the dose per unit time initially injected [7]. Various other studies on the safety and tolerability of the specific immunotherapy protocols came to similar re- 


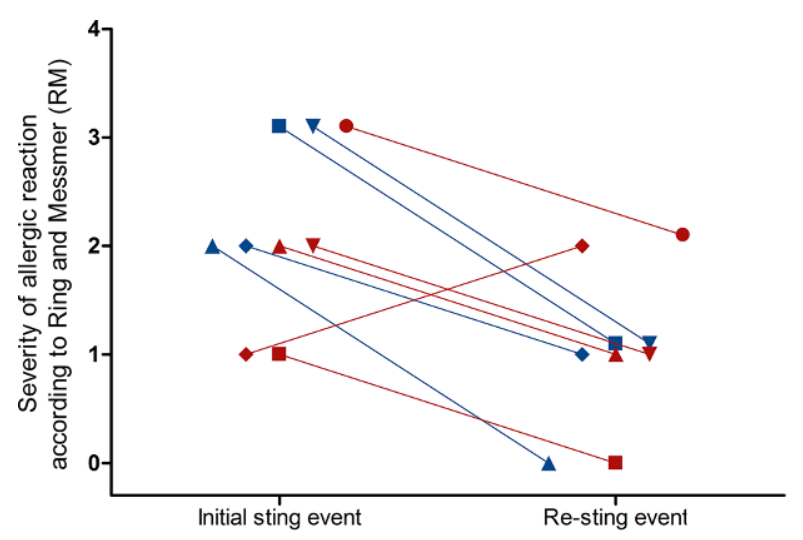

- Patient 1 (m;3-1)

- Patient $2(\mathrm{~m} ; 2-0)$

$=$ - Patient 3 (f;1-0)

$\rightarrow$-Patient $4(\mathrm{~m} ; 3-1)$

$\multimap$ Patient $5(\mathrm{~m} ; 2-1)$

\-Patient 6 (f;2-1)

$\rightarrow$ Patient $7(\mathrm{f} ; 2-1)$

$\checkmark$ Patient 8 (f;1-2)

- Patient 9 (f;3-2)

a

Sting event

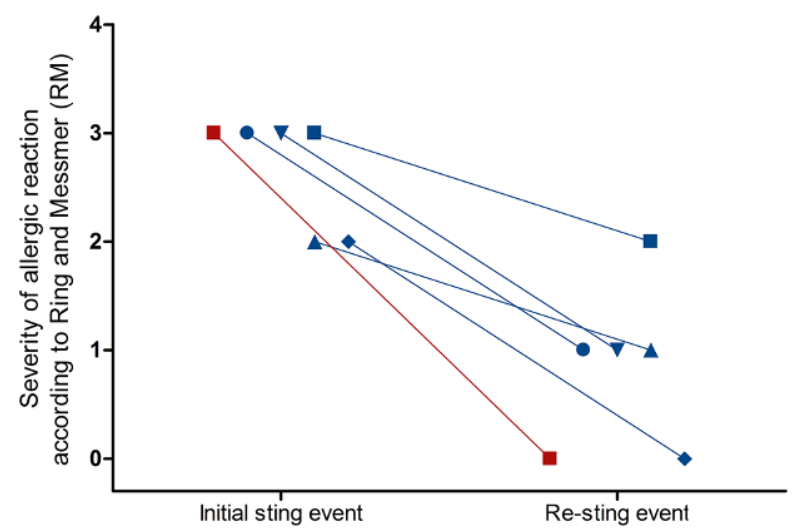

b

Fig. 4 Severity of allergic reaction according to Ring and Messmer [13] to accidental sting events after completion of HG-AIT. a Data of the patient group with bee venom allergy.
- Patient $10(\mathrm{~m} ; 3-2)$

- Patient $11(\mathrm{~m} ; 2-1)$

$\checkmark$-Patient $12(\mathrm{~m} ; 3-1)$

-Patient $13(\mathrm{~m} ; 2-0)$

- Patient 14 (f;3-0)

- Patient $15(\mathrm{~m} ; 3-1)$

Fig. 5 Quality of life questionnaire for Insect venom allergy (VQLQ-d) score

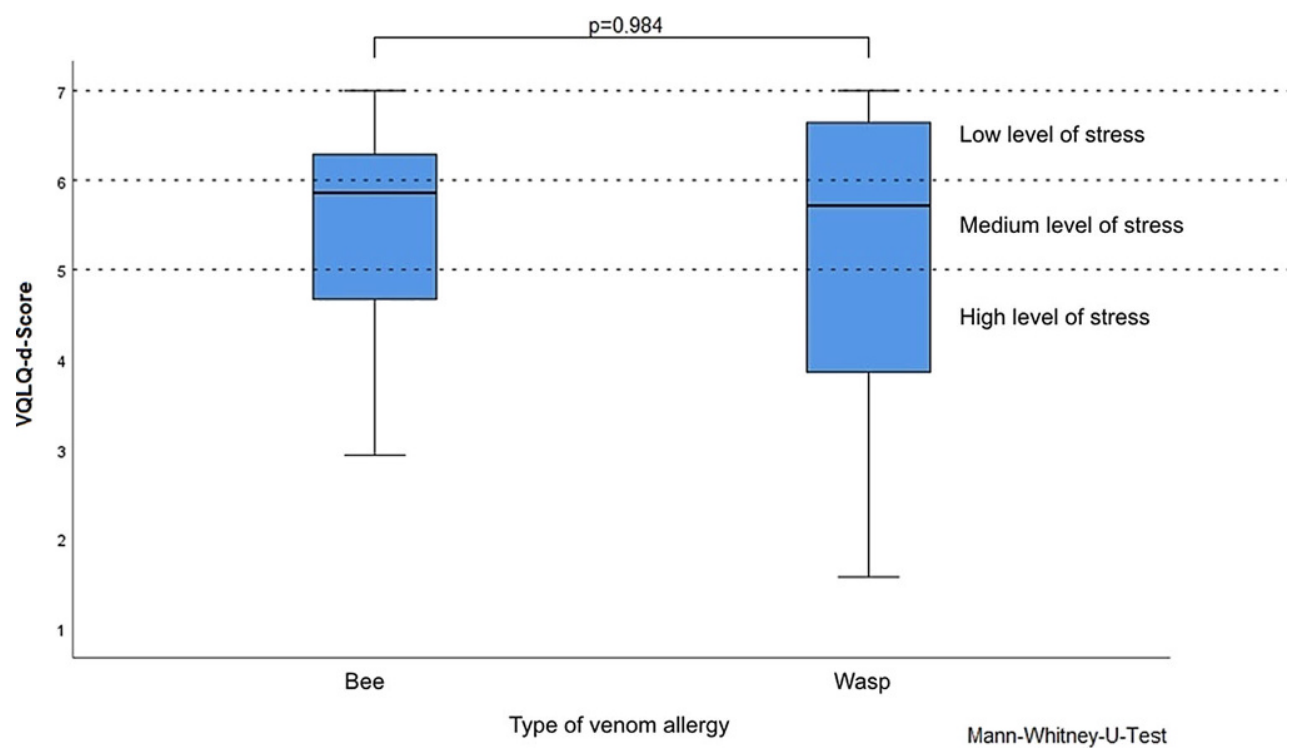

b Data of the patient group with wasp venom allergy. c Aggregated values (mean). $H G-A I T$ hymenoptera venom allergen immunotherapy, mean arithmetic mean, $m$ male, $w$ female

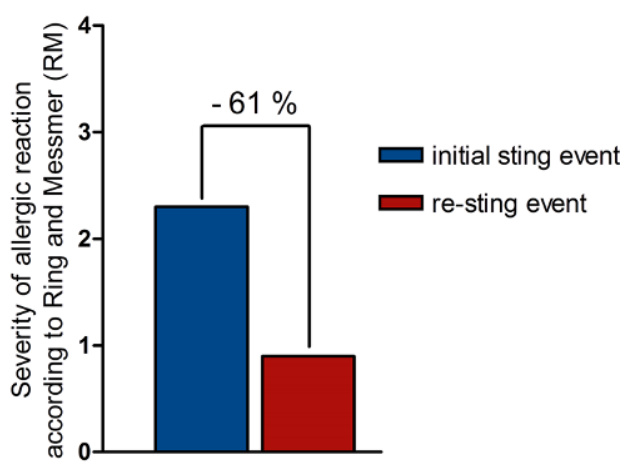

Re-sting event

after completion of AIT 
Fig. 6 Quality of Life Questionnaire in Insect Venom Allergy (VQLQ-d) score and clinical response after field sting, during allergen immunotherapy (AIT)

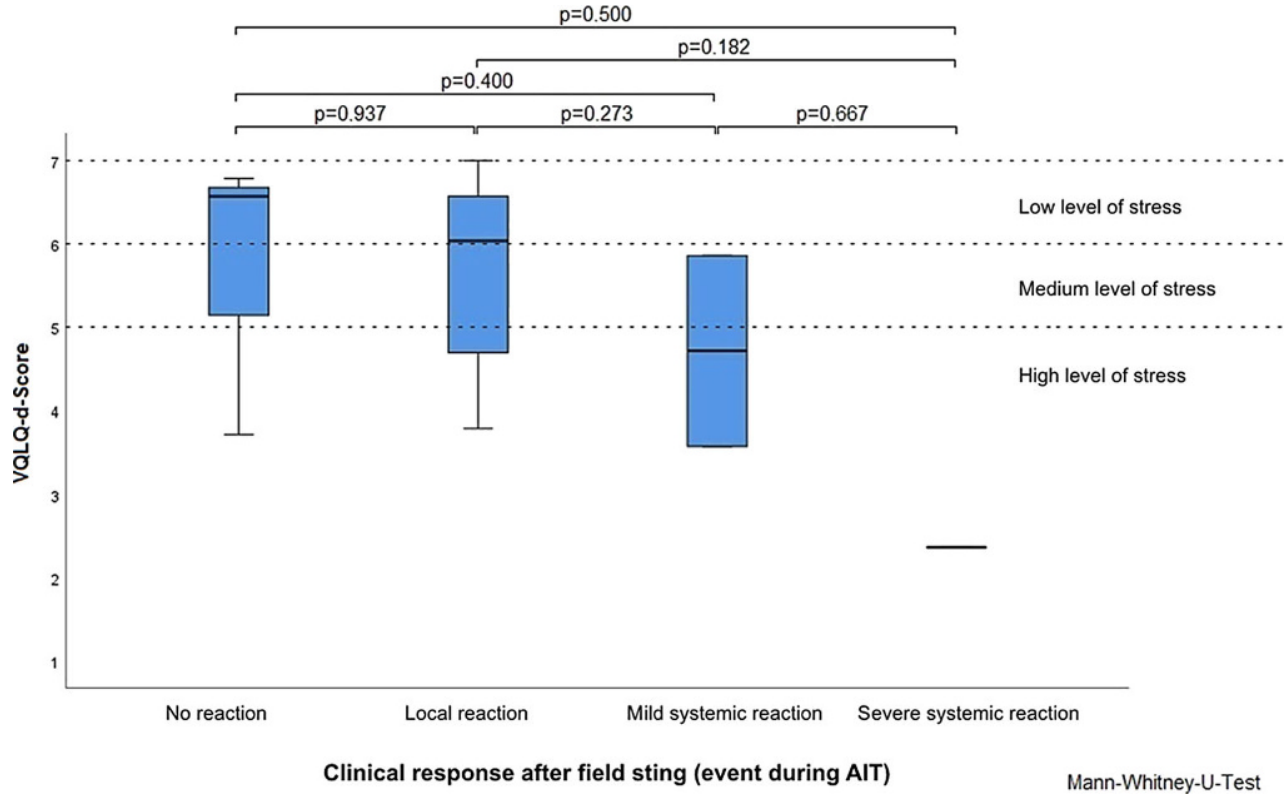

Fig. 7 Quality of Life Questionnaire for Insect Venom Allergy (VQLQ-d) score and clinical response to field sting after allergen immunotherapy (AIT)

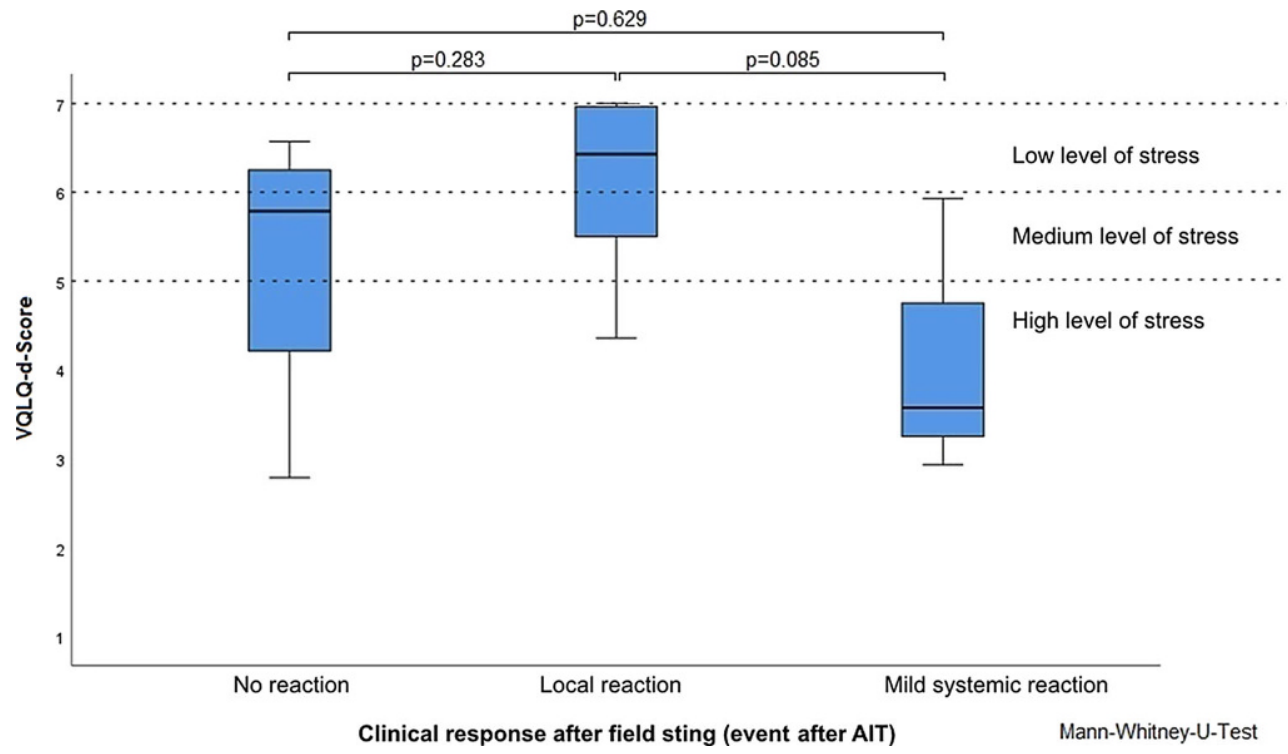

sults. The efficacy of AIT in adults is reported to be 77-84\% for bee venom and $91-96 \%$ for wasp venom [2]. As a possible cause for the poorer response of AIT with bee venom, higher venom amounts after bee sting and a broader sensitisation profile are discussed [20]. Some affected individuals show an isolated sensitisation to Api m 10, which may be underrepresented in some available therapeutic venom extracts due to different purification processes by manufacturers [21].

Despite the overall positive experience, adverse events must be expected with HG-AIT. The side effect rates of HG-AIT are between 5 and $40 \%$. In most cases, more side effects are observed with the bee venom than with the wasp venom. Adequate emergency therapy must also be possible at all times during continued treatment in the outpatient setting $[20,22]$. Maintenance therapy should be given for at least 3-5 years. After 3 years at the earliest, it can be pragmatically terminated in patients if an accidental sting has confirmed the effectiveness, cutaneous sensitisation is less than initially or specific IgE antibodies are below the baseline value or no longer detectable. The success of AIT cannot be predicted by laboratory parameters or other tests $[1,2]$.

Sting provocations to check the success of therapy are not yet common in children; among other things, the amount of toxin delivered during a bite can vary considerably, so that reliable conclusions are not possible. With regard to the effectiveness of HG-AIT after cessation, the data situation seems to be more favourable in children than in adults. Only 5\% recurrences are reported 20 years after cessation of HG-AIT [2]. However, it is noteworthy that in our study, $20 \%$ of patients reacted to a field prick with a mild systemic 
Fig. 8 VQLQ-d in patients with and without emergency set. VQLQ-d Quality of Life Questionnaire for Insect Venom Allergy

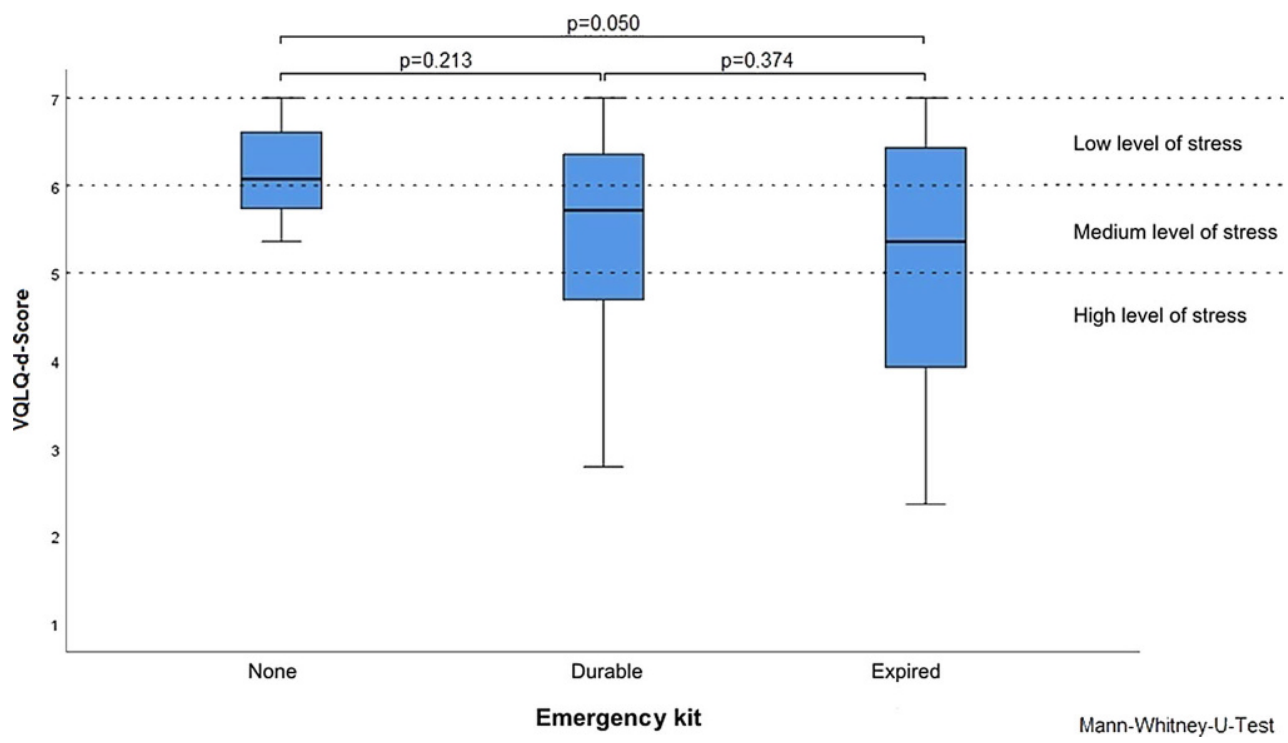

Fig. 9 Subjective improvement in quality of life after allergen immunotherapy (AIT)

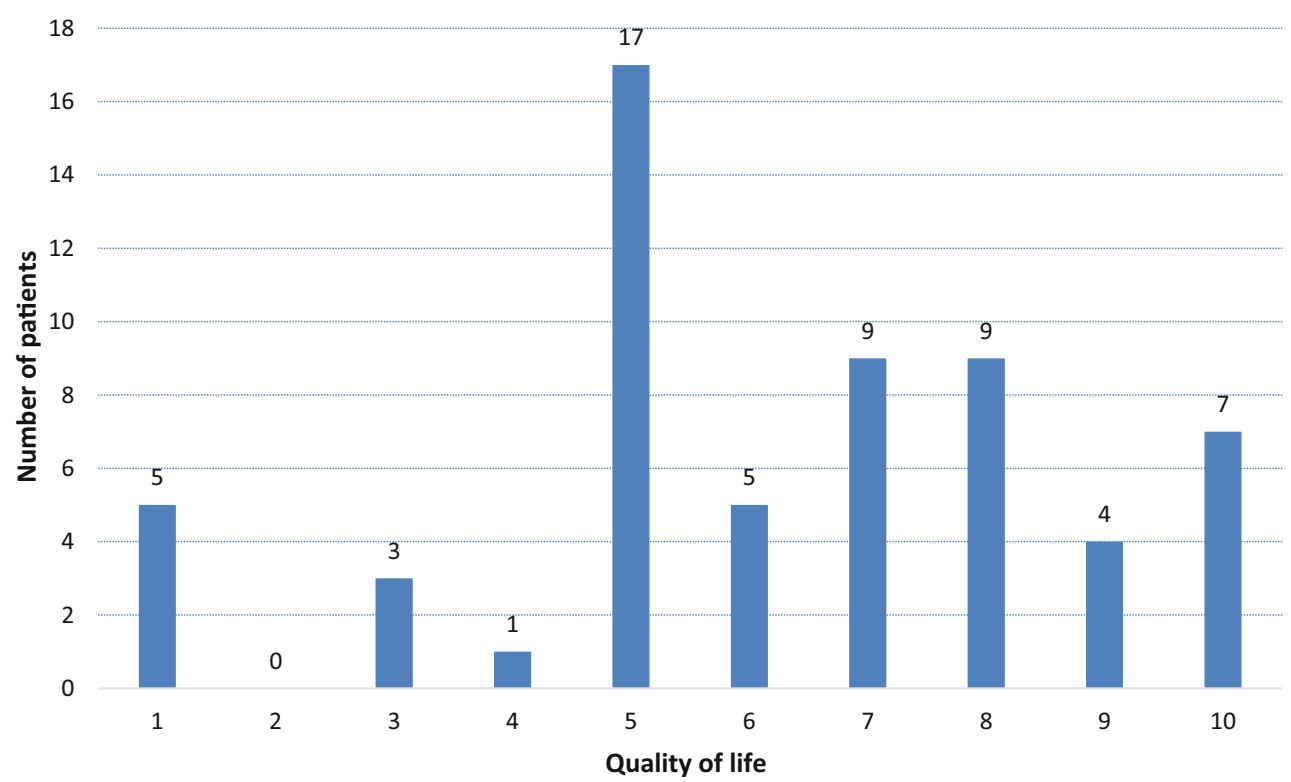

reaction after the end of HG-AIT. Ertoy Karagol et al. reported a systemic reaction after re-sting in $16.6 \%$ $(n=1)$ of 22 children studied [23]. Studies with sufficient numbers of subjects on tolerance loss after AIT in childhood are rare. Long-term effects of AIT in insect venom allergy show that the majority of patients are usually protected. However, in adults, up to $55 \%$ of patients are expected to have a recurrent systemic reaction to a sting [24]. The frequency of recurrence is higher in patients with bee venom allergy than in those with wasp venom allergy $[25,26]$. Only few valid data on this topic are available for childhood [12]. In our study, $48 \%$ of patients were stung again during or after the end of HG-AIT. However, at follow-up, these patients showed a reduction in RM severity to the field sting of $61 \%$.

The question of carrying an adrenaline auto-injector during and after HG-AIT is consistently contro- versial, as patients are protected after reaching the maintenance dose. Even within the EAACI guideline, no consensus could be reached. The physician is thus given discretionary powers for prescribing [2]. The German guideline, currently under revision, recommends carrying emergency medication after the end of HG-AIT [1]. Although all patients were prescribed an emergency kit after the index event, according to patient information $14 \%$ could not remember it after the end of HG-AIT; in almost $40 \%$ the expiry date had already passed. Considering that these are patients after an anaphylactic reaction, these results are alarming [27].

In recent years, the assessment of quality of life with allergic diseases has also become the focus of health services research in childhood and adolescence [28-31]. Fischer et al. 2011 were able to show that with the VQLQ-d a simple, quick to administer, easy 
to evaluate and reliable questionnaire for assessing quality of life or somatopsychic stress in bee and wasp venom allergy in adulthood is available [32]. We were able to show that the disease-specific quality of life of patients after the end of HG-AIT in childhood and adolescence is still considered high in young adulthood.

In terms of quality of life bee venom allergic patients tend to benefit slightly more than wasp venom allergic patients in terms of quality of life [18], although no significance was detectable in our study. The sole prescription of an epinephrine auto-injector as emergency medication without performing HG-AIT led to a decrease in the specific quality of life with psychological distress of the patients [33]. Many studies show that HG-AIT not only improves disease-specific quality of life, but also reduces allergy-related anxiety in patients [10]. We were also able to confirm that AIT for insect venom allergy in childhood and adolescence is not only very effective in preventing a recurrence of sting anaphylaxis, but also leads to a lower burden in terms of quality of life in the adolescent or adult patients. It must be taken into account that our study included a relatively small number of patients and did not comprise an untreated control group. In order to be able to assess the long-term influence of HG-AIT in detail with regard to emotional aspects and quality of life, prospective studies with age-adapted questionnaires for childhood and adolescence are urgently needed.

Due to the shortened inpatient hospital stay, the HG-AIT according to the ultra-rush treatment causes increased acceptance especially in children and adolescents and is safe and well tolerated. However, the results also document large gaps between the recommendations formulated by experts and the measures implemented in the reality of care, especially in the area of follow-up care and handling of the emergency kit. Patients after HG-AIT should be routinely followed up. Manmohan et al. have already pointed out that patients with insect venom anaphylaxis should ideally be informed about the possibilities of urgently needed diagnostics and therapy options while still undergoing acute treatment [34]. In the field of insect venom allergy, we now have excellent diagnostics and, with HG-AIT, a highly effective therapeutic option $[1,2$, 35]; however, we still fail to provide optimal care for affected children and adolescents according to guidelines. To improve the situation, patients with insect venom allergy should therefore be continuously cared for by doctors with further training in allergology.

Funding Open Access funding enabled and organized by Projekt DEAL.

Conflict of interest J.-O. Steiß has received grants and/or honoraria from ALK-Abello, Allergopharma, Bencard Allergie $\mathrm{GmbH}$, Novartis Pharma $\mathrm{GmbH}$, outside the present work. C. Weber and M. Becker declare that they have no competing interests.
Open Access This article is licensed under a Creative Commons Attribution 4.0 International License, which permits use, sharing, adaptation, distribution and reproduction in any medium or format, as long as you give appropriate credit to the original author(s) and the source, provide a link to the Creative Commons licence, and indicate if changes were made. The images or other third party material in this article are included in the article's Creative Commons licence, unless indicated otherwise in a credit line to the material. If material is not included in the article's Creative Commons licence and your intended use is not permitted by statutory regulation or exceeds the permitted use, you will need to obtain permission directly from the copyright holder. To view a copy of this licence, visit http://creativecommons.org/licenses/by/4.0/.

\section{References}

1. Przybilla B, Ruëff F, Walker A, Räwer H, Aberer W, Bauer CP, et al. Diagnose und Therapie der Bienen- und Wespengiftallergie. Leitlinie der Deutschen Gesellschaft für Allergologie und klinische Immunologie (DGAKI), des Ärzteverbandes Deutscher Allergologen (ÄDA), der Gesellschaft für Pädiatrische Allergologie und Umwelt-medizin (GPA), der Deutschen Dermatologischen Gesellschaft (DDG) und der Deutschen Gesellschaft für Kinder- und Jugendmedizin (DGKJ) in Zusammenarbeit mit der Österreichischen Gesellschaft für Allergologie und Immunologie (ÖGAI) und der Schweizerischen Gesellschaft für Allergologie und Immunologie (SGAI). Allergo J.2011;20:318-39.

2. Sturm GJ, Varga EM, Roberts G, Mosbech H, Bilò MB, Akdis CA, et al. EAACI guidelines on allergen immunotherapy: hymenoptera venom allergy. Allergy. 2018;74:744-64.

3. Ring J, Beyer K, Biedermann T, Bircher A, Fischer M, Fuchs T, et al. Leitlinie zu Akuttherapie und Management der Anaphylaxie - Update 2021. S 2k-Leitlinie der Deutschen Gesellschaft für Allergologie und klinische Immunologie (DGAKI), des Ärzteverbands Deutscher Allergologen (AeDA), der Gesellschaft für Pädiatrische Allergologie und Umweltmedizin (GPA), der Deutschen Akademie für Allergologie und Umweltmedizin (DAAU), des Berufsverbands der Kinder- und Jugendärzte (BVKJ), der Gesellschaft für Neonatologie und Pädiatrische Intensivmedizin (GNPI), der Deutschen Dermatologischen Gesellschaft (DDG), der Österreichischen Gesellschaft für Allergologie und Immunologie (ÖGAI), der Schweizerischen Gesellschaft für Allergologie und Immunologie (SGAI), der Deutschen Gesellschaft für Anästhesiologie und Intensivmedizin (DGAI), der Deutschen Gesellschaft für Pharmakologie (DGP), der Deutschen Gesellschaft für Pneumologie und Beatmungsmedizin (DGP), der Patientenorganisation Deutscher Allergie- und Asthmabund (DAAB) und der Arbeitsgemeinschaft Anaphylaxie - Training und Edukation (AGATE). Allergo J Int. 2021;30:1-25.

4. Li JT, Lockey RF, Bernstein IL, Portnoy JM, Nicklas RA. Allergen immunotherapy: a practice parameter. Ann Allergy Asthma Immunol. 2003;90:1-40.

5. Lange J, Cichocka-Jarosz E, MarczakH, Krauze A, Tarczon I, Swiebocka E, et al. Natural history of Hymenoptera venom allergy in children not treated with immunotherapy. Ann Allergy Asthma Immunol. 2016;116:225-9.

6. Lee HH, Landeck L, Stefaniak R, Zuberbier T, Worm M. Verträglichkeit der spezifischen Wespengift-Immuntherapie nach einem rush- oder ultra-Rush-Protokoll: eine prospektive vergleichende Untersuchung. Allergo J. 2005;14:482-6.

7. SteißJO, Hüls G, Gortner L, Lindemann H. Ein modifiziertes Ultra-Rush-Verfahren der spezifischen Immuntherapie bei 
Kindern und Jugendlichen mit einer Insektengiftallergie. Klin Padiatr. 2004;216:79-82.

8. Steiß JO, Jödicke B, Lindemann H. A modified ultrarush insect venom immunotherapy protocol for children. Allergy Asthma Proc. 2006;27:148-50.

9. Nittner-Marszalska M, Cichocka-Jarosz E, Małaczyńska T, Kraluk B, Rosiek-Biegus M, Kosinska M, et al. Safety of ultrarush venom immunotherapy: comparison between children and adults. J Investig Allergol Clin Immunol. 2016;26:40-7.

10. Confino-Cohen R, Melamed S, Goldberg A. Debilitating beliefs and emotional distress in patients given immunotherapy for insect sting allergy: a prospective study. Allergy Asthma Proc. 2009;30:546-51.

11. Cichocka-Jarosz E, Brzyski P, Tobiasz-Adamczyk B, Lis G, PietrzykJJ. Development of children's hymenoptera venom allergy quality of life scale (CHVAQoLS). Clin Transl Allergy. 2013;3:25

12. Golden DB, Kagey-Sobotka A, Norman PS, Hamilton RG, Lichtenstein LM. Outcomes of allergy to insect stings in children, with and without venom immunotherapy. NEngl JMed. 2004;351:668-74.

13. Ring J, Meßmer K. Incidence and severity of anaphylactoid reactions to colloid volume substitutes. Lancet. 1977;1:466-9.

14. van der Zwan JC, Flinterman J, Jankowski IG, Kerckhaert JAM. Hyposensitisation to wasp venom in six hours. BrMed J (Clin Res Ed). 1983;287:1329-31.

15. Köhli-WiesnerA, Stahlberger L, BieliC, StrickerT, Lauener R. Induction of specific immunotherapy with Hymenoptera venoms using ultrarush regimen in children: safety and tolerance. JAllergy (Cairo). 2012;2012:790910. https://doi. org/10.1155/2012/790910.

16. Bucher C, SchwagerS, Schmid-Grendelmeier P,Wüthrich B. Sicherheit der Ultrarush-Hyposensibilisierung mitBienenund Wespengift. Allergo J. 2003;12:562-5.

17. Çetinkaya PG, Esenboğa S, Uysal Soyer Ö, Tuncer A, Şekerel BE, Şahiner ÜM. Subcutaneous venom immunotherapy in children: efficacy and safety. Ann Allergy Asthma Immunol. 2018;120:424-8.

18. Nowak N, Bazan-Socha S, Pulka G, Pełka K, Latra P. Evaluation of the quality of life in subjects with a history of severe anaphylactic reaction to the Hymenoptera venom. Pneumonol Alergol Pol. 2015;83:352-8.

19. Čelesnik Smodiš N, Šilar M, Eržen R, Rijavec M, Košnik M, Korošec P. Down-regulation of FceRI-mediated CD63 basophil response during short-term VIT determined venomnonspecific desensitization. PLoS One. 2014;9:e94762.

20. Adib-Tezer H, Bayerl C. Honeybee and wasp venom allergy: sensitization and immunotherapy. J Dtsch Dermatol Ges. 2018;16:1228-47.

21. Blank S, Seismann H, Michel Y, McIntyre M, Cifuentes L, Braren I, et al. Api m 10, a genuine A. mellifera venom allergen, is clinically relevant but underrepresented in therapeutic extracts. Allergy. 2011;66:1322-9.

22. Bilò MB, Pravettoni V, Bignardi D, Bonadonna P, Mauro M, Novembre E, et al. Hymenoptera venom allergy: management of children and adults in clinical practice. J Investig Allergol Clin Immunol. 2019;29:180-205.

23. Etoy Karagol HI, Bakirtas A, Yilmaz O, Topal E, Arga M, Demirsoy MS, et al. Long-term follow-up of re-sting reactions in children with moderate to severe venom hypersensitivity. Eur J Pediatr. 2015;174:891-6.

24. Adelmeyer J, Pickert J, Pfützner W, Möbs C. Langfristige Auswirkungen der Allergen-Immuntherapie mit Hymenopterengift auf den klinischen Verlauf, immunologische Parameter und psychosoziale Aspekte. Allergo Select. 2021;44:139-50.

25. RuëffF, Przybilla B. Insektengifthyposensibilisierung. Hautarzt. 2008;59:200-5.

26. Hafner T, DuBuske L, Kosnik M. Long-term efficacy of venom immunotherapy. Ann Allergy Asthma Immunol. 2008;100:162-5.

27. Fiedler C, Miehe U, Treudler R, Kiess W, Prenzel F. Longterm follow-up of children after venom immunotherapy: low adherence to anaphylaxis guidelines. Int Arch Allergy Immunol. 2017;172:167-72.

28. Brzyski P, Cichocka-Jarosz E, Lis G, Tobiasz-Adamczyk B. Development of parents' of children with hymenoptera venom allergy quality of life scale (poCHVAQoLS). Postepy Dermatol Alergol. 2015;32:143-53.

29. Koschel D. Beeinträchtigung der Lebensqualität bei Patienten mit Insektengiftallergie. Allergo J Int. 2017;26:88-92.

30. Oude Elberink JN, van der Heide S, Guyatt GH, Dubois AE. Analysis of the burden of treatment in patients receiving an EpiPen for yellow jacket anaphylaxis. J Allergy Clin Immunol. 2006;118:699-704.

31. Koschel DS, Schmies M, Weber CN, Höffken G, Balck F. Tolerated sting challenge in patients on hymenoptera venom immunotherapy improves health-related quality of life. J Investig Allergol Clin Immunol. 2014;24:226-30.

32. FischerJ, FeidtA, Giel KE, Martens U,ZipfelS, BiedermannT, et al. Quality-of-life in wasp venom allergy-validation of the Germanversion of the "vespidallergyquality oflifequestionnaire" (VQLQ-d). J Dtsch Dermatol Ges. 2011;9:379-85.

33. OudeElberinkJN, de MonchyJG, Golden DB, BrouweerJLP, Guyatt GH, Dubois AE. Development and validation of a health-related quality-of-life questionnaire in patients with yellow jacket allergy. J Allergy Clin Immunol. 2002;109:162-70.

34. Manmohan M, Müller S, Rauber MM, Koberne F, Reisch H, Koster J, et al. Current state of follow-up care for patients with hymenoptera venom anaphylaxis in southwest Germany: major impact of early information. Allergo J Int. 2018;27:4-14.

35. Tan JW, Campbell DE. Insect allergy in children. J Paediatr Child Health. 2013;49:E381-7. 